\title{
Genetic parameters of adaptive immune response traits in Canadian Holsteins
}

\author{
K. A. Thompson-Crispi, ${ }^{\star 1}$ A. Sewalem, $† \ddagger$ F. Miglior, $† \ddagger$ and B. A. Mallard ${ }^{\star}$ \\ ${ }^{*}$ Department of Pathobiology, University of Guelph, Guelph, Ontario, N1G 2W1, Canada \\ †Guelph Food Research Center, Agriculture and Agri-Food Canada, Guelph, Ontario, N1G 5C9, Canada \\ ¥Canadian Dairy Network, Guelph, Ontario, N1K 1E5, Canada
}

\begin{abstract}
The objectives of this study were to estimate genetic parameters of cell-mediated (CMIR) and antibody-mediated (AMIR) immune response (IR) traits of Holstein cattle on a national scale and to associate estimated breeding values of CMIR, AMIR, and overall IR with routinely evaluated traits in Canada. In collaboration with the Canadian Bovine Mastitis Research Network, 445 Holstein cows from 42 herds across Canada were immunized to measure delayed-type hypersensitivity as an indicator of CMIR and serum antibody for AMIR to putative type 1 and type 2 test antigens, respectively. Primary (d 14) and secondary (d 21) AMIR were measured for both IgG1 and IgG2. A series of uni- and bivariate linear animal models were used to estimate genetic parameters and breeding values for CMIR and the 4 AMIR traits. The models included the fixed effects of parity and stage of lactation and the random effects of herd-technician, animal, and residual. Heritability of CMIR was $0.19(\mathrm{SE}=0.10)$ and for AMIR traits ranged from 0.16 to 0.41 (SE $=0.09-0.11$ ) depending on time and antibody isotype. The genetic correlations between CMIR and AMIR were negative and ranged from -0.13 to -0.45 ( $\mathrm{SE}=0.32-0.46$ ). The results indicate adaptive immune response traits are moderately heritable and provide a potential for genetic selection. The negative genetic correlations between CMIR and AMIR indicate the importance of considering both traits in breeding for overall disease resistance. Significant beneficial associations between the reproductive traits number of services and first service to conception were found, which may indicate these reproductive traits would improve with genetic selection for enhanced immune response.
\end{abstract}

Key words: immune response, Holstein cow, health, genetic parameter

Received April 14, 2011

Accepted September 19, 2011.

${ }^{1}$ Corresponding author: kthomp02@uoguelph.ca

\section{INTRODUCTION}

Genetic selection for production has been associated with increases in disease incidence and the associated costs in dairy cattle (Shook, 1989; Heringstad et al., 2005). The immune system is vital to the control of infectious and other diseases, and the inclusion of immune response (IR) traits in breeding indices has been suggested to decrease the incidence and impact of disease in livestock (Abdel-Azim et al., 2005; Mallard et al., 2011). Holstein cows with superior or high IR have been shown to have lower occurrence of mastitis, improved response to commercial vaccine, and increased milk and colostrum quality (Wagter et al., 2000). HighIR cows have also been shown to have decreased incidence of diseases such as mastitis, metritis, ketosis, and retained placenta (De La Paz, 2008). Therefore, genetic selection for overall immune responsiveness may be a feasible approach to improve inherent disease resistance in dairy cattle.

Animals tend to respond to intracellular pathogens, such as Mycobacterium avium subspecies paratuberculosis, by mounting a cell-mediated IR (CMIR) and respond to extracellular pathogens, such as Escherichia coli, by an antibody-mediated IR (AMIR). Although in dairy cattle these adaptive IR traits have been shown to be negatively genetically correlated (Hernández et al., 2006), CMIR and AMIR work in concert to provide optimal host protection to a variety of challenges. Antigens preferentially induce production of cytokines that steer CMIR and AMIR. Type 1 antigens induce production of cytokines such as IFN- $\gamma$ and IL-12, which guide a CMIR, and type 2 antigens induce production of IL-4, IL-10, and IL-13, which propagate an AMIR (Crawley et al., 2005). Immunoglobulin production is also associated with IR type: IgG2 characteristic of CMIR and IgG1 of AMIR (Estes and Brown, 2002). Cell-mediated IR and AMIR tend to be dichotomous, as the cytokines that amplify one response can dampen the other (Brown et al., 1998). It is, therefore, important to consider both CMIR and AMIR to genetically enhance dairy cattle for broad-based disease resistance to the multitude of pathogens. 
A patented protocol (US Patent \#7,258,858; Wagter-Lesperance and Mallard, 2007) to evaluate CMIR and AMIR has been developed (Wagter et al., 2000; Hernández et al., 2005) and shown to be a safe, reliable method to assess IR in dairy cattle. Cows are immunized with putative type 1 and type 2 test antigens (Hine et al., 2011) to stimulate CMIR and AMIR, respectively. Delayed-type hypersensitivity to the type 1 antigen is used as an indicator of CMIR, and serum antibody (IgG1 and IgG2) to the type 2 antigen at multiple time points is used as an indicator of AMIR.

The heritability of IR traits in cattle have been estimated previously and found to be moderate, indicating that it would be feasible to breed for enhanced IR. The heritability of CMIR was found to range from 0.19 to 0.42 (Hernández et al., 2006) and 0.19 to 0.64 for AMIR (Mallard et al., 1983; Wagter et al., 2000; Hernández et al., 2006). These studies were each performed on either 1 or a limited number of dairy herds in 1 region of Canada. Therefore, the objectives of this study were to (1) estimate the genetic parameters of CMIR and AMIR for Holstein cows from numerous commercial herds across Canada and (2) associate EBV of CMIR, AMIR, and overall IR with routinely evaluated traits in Canada. These data are expected to provide further insight into the feasibility of including IR in breeding indices to improve inherent animal health.

\section{MATERIALS AND METHODS}

\section{Animals}

The IR of 445 lactating Holsteins, outside the peripartum period, from 42 herds across Canada was evaluated (Thompson-Crispi and Mallard, 2011) in collaboration with the Canadian Bovine Mastitis Research Network (CBMRN). Lactating cows enrolled in the longitudinal incidence density mastitis sampling for the CBMRN also had IR testing as per Reyher et al. (2011). Ten cows expected to remain in the herd for at least 2 mo were chosen at random and 5 cows that had most recently calved. Immune response was tested between July 2007 and August 2008. The distribution by parity was as follows: $\mathrm{n}=138$ in parity $1, \mathrm{n}=134$ in parity $2, \mathrm{n}=76$ in parity 3 , and $\mathrm{n}=97$ in parity 4 or higher. All experimental procedures were approved by the Animal Care Committee of the University of Guelph under guidelines of the Canadian Council of Animal Care.

\section{Immunization Protocol}

Cows at least 28 DIM were immunized to induce CMIR and AMIR outside the peripartum period.
Delayed-type hypersensitivity to Candida albicans, a type-1 test antigen, was used as an indicator of CMIR (Hernández et al., 2005). Primary and secondary antibody production to a type-2 test antigen, hen egg white lysozyme (HEWL), was used as an indicator of AMIR (Heriazon et al., 2009b). On d 0 and 14, cows received an intramuscular injection of $0.5 \mathrm{mg}$ of HEWL (SigmaAldrich Canada Ltd., Oakville, ON, Canada), $0.5 \mathrm{mg}$ of Candida albicans (Greer Laboratories Inc., Lenoir, $\mathrm{NC}$ ), and $0.5 \mathrm{mg}$ of Quil-A adjuvant (Cedarlane Laboratories Ltd., Hornby, ON, Canada) dissolved in $1 \mathrm{~mL}$ PBS (PBS, pH 7.4). Using a 22 gauge needle, a $1.0 \mathrm{~mL}$ injection was divided and administered intramuscularly on both sides of the neck or rump.

\section{Delayed-Type Hypersensitivity}

Delayed-type hypersensitivity was measured as the increase in skin-fold thickness to the type 1 test antigen (Heriazon et al., 2009b). On d 21 of the immunization protocol, baseline skin-thickness measurements were taken in triplicate on both sides of the tail fold, using spring-loaded calipers (Harpenden Skinfold Caliper; Creative Health Products Inc., Ann Arbor, MI). Cows received an intradermal injection of $0.1 \mathrm{mg}$ of Candida albicans in $0.1 \mathrm{~mL}$ of PBS in the right tail fold (test site), and $0.1 \mathrm{~mL}$ of a PBS control on the left side (control site), using a 28 -gauge needle. On d 23, 48 h later, triplicate skin-thickness measurements were repeated at the test and control sites. Data was log-transformed for a normal distribution.

\section{Serum Antibody}

Blood was collected on d 0, 14, and 21 of the immunization protocol to evaluate serum antibody to the type-2 test antigen by a modified ELISA. The negative control was fetal calf serum, and the positive control was pooled from d 21 sera after 2 immunizations. Flatbottomed 96-well polystyrene plates were coated with $0.144 \mathrm{mg}$ of HEWL dissolved in $1 \mathrm{~mL}$ of carbonatebicarbonate buffer $\left(\mathrm{pH}\right.$ 9.6) and incubated at $4^{\circ} \mathrm{C}$ for $24 \mathrm{~h}$. Plates were washed with PBS and $0.05 \%$ Tween 20 (Sigma-Aldrich Canada Ltd.; wash buffer pH 7.4) 3 times and blocked with PBS, 3\% Tween 20, 1.5\% BSA, and $1.5 \%$ fetal calf serum for $1 \mathrm{~h}$ at room temperature (RT), and then washed again 3 times. Control sera were applied in quadruplicate and test sera in duplicate in a quadrant pattern. Sera were diluted in wash buffer at $1 / 50$ and $1 / 200$ and incubated for $2 \mathrm{~h}$ at RT. Plates were washed 5 times, and secondary antibody, sheep anti-bovine IgG1 or IgG2 conjugated to alkaline phosphatase (Bethyl Laboratories Inc., Montgomery, TX) was dissolved in Tris-Tween buffer with $0.05 \%$ Tween 
20 (pH 7.4) and incubated at RT for $1 \mathrm{~h}$. All wash steps were performed with the Elx405 Auto Plate Washer (BioTek Instruments Inc., Winooski, VT). $p$-Nitrophenyl phosphate substrate system (Sigma-Aldrich Canada Ltd.) was added and incubated for approximately 50 min at RT and optical density (OD) values at $405 \mathrm{~nm}$ were obtained using the EL808 (BioTek Instruments Inc.) plate reader. Data was collected with KC Junior Software (BioTek Instruments Inc.). Optical density values were corrected to the rolling mean of the positive control as described previously (Heriazon et al., 2009a) to account for day and plate variation. The dilutions of the corrected OD values were summed and duplicates averaged for statistical analysis.

\section{Statistical Analysis}

Complete records for CMIR and AMIR at d 14 and 21 for IgG1 and IgG2 isotypes and cow registration numbers were available for 445 cows. The full pedigree records file included a total of 29,336 animals and was provided by the Canadian Dairy Network (Guelph, Ontario).

To determine the increase in skin-fold thickness for CMIR, the $\log$ ratio of thickness in millimeters after $48 \mathrm{~h}$ at the test site $/ 0 \mathrm{~h}$ at the test site was the response variable, with the log ratio of the control site fit as a covariate. Log-transformation was performed to normalize the data. For AMIR, the d-0 values were fit as a covariate for $\mathrm{d} 14$ and 21 as a measure of primary and secondary antibody responses, respectively. Cellmediated IR and AMIR were analyzed using a series of uni- and bivariate linear animal models as follows:

$$
\begin{aligned}
y_{i j k l m}=\mu & +h t_{i}+p_{j}+\alpha \times s t+\beta \times s t^{2} \\
& +\gamma \times d_{k}+c_{l}+e_{i j k l m},
\end{aligned}
$$

where $y_{i j k l m}=$ CMIR or AMIR at d 14 or 21 for IgG1 or IgG2; $\mu=$ overall mean; $h t_{i}=$ random effect of herdtechnician (42 herds and 9 technicians); $p_{j}=$ fixed effect of parity $(1,2,3$, and $\geq 4)$; st $=$ stage of lactation measured as DIM as a linear effect of DIM and $s t^{2}=$ stage of lactation squared; $d_{k}=$ control site for CMIR or $\mathrm{d} 0$ data for AMIR as fixed regressions; $\alpha, \beta$, and $\gamma$ $=$ regression coefficients; $c_{l}=$ random effect of cow; and $e_{i j k l m}=$ residual error.

In matrix form, the multiple trait animal model is

$$
\mathbf{y}=\mathbf{X b}+\mathbf{Z}_{1} \mathbf{h t}+\mathbf{Z a}+\mathbf{e},
$$

where $\mathbf{y}$ is the matrix for CMIR and AMIR at d 14 and 21 for $\operatorname{IgG} 1$ and $\operatorname{IgG} 2 ; \mathbf{X}, \mathbf{Z}_{1}$, and $\mathbf{Z}$ are the incidence matrices related to the fixed and random effects, respec- tively; $\mathbf{b}$ is the vector that contains the fixed effects; ht is the vector of random effects of herd-technician; $\mathbf{a}$ is the vector of random additive genetic effects of cow; and $\mathbf{e}$ is the vector of random residual effect. The expectations (E) and assumed variance $(\mathbf{V})$ are $\mathbf{E}(\mathbf{y})=$ $\mathbf{X b} ; \mathbf{E}(\mathbf{h t})=\mathbf{E}(\mathbf{a})=\mathbf{E}(\mathbf{e})=0 ; \mathbf{V}(\mathbf{h t})=\mathbf{H T} ; \mathbf{V}(\mathbf{a})=$ $\mathbf{G} ; \mathbf{V}(\mathbf{e})=\mathbf{R} ; \operatorname{cov}\left(\mathbf{a}, \mathbf{e}^{\prime}\right)=0$; and $\mathbf{V}(\mathbf{y})=\mathbf{Z G} \mathbf{Z}^{\prime}+\mathbf{H T}$ $+\mathbf{R}$, where $\mathbf{H T}$ is the direct product of an identity matrix (I) of order of the number of herd-technicians and the matrix of herd-technician variances $\left(\mathbf{I} \otimes \mathbf{h t}_{\mathbf{0}}\right)$; $\mathbf{G}$ is the direct product of the numerator relationship matrix (A) for animals and the matrix of genetic variance and covariance $\left(\mathbf{A} \otimes \mathbf{G}_{\mathbf{0}}\right)$; and $\mathbf{R}$ is the direct product of an identity matrix of order of the number of observations and the matrix of error variances and co-variances $(\mathbf{I} \otimes$ $\mathbf{R}_{\mathbf{0}}$ ). Heritability values were calculated as

$$
h^{2}=\sigma_{a}^{2} /\left(\sigma_{a}^{2}+\sigma_{h t}^{2}+\sigma_{e}^{2}\right) .
$$

The genetic analysis was performed with DMU software using an average information restricted maximum likelihood (AI-REML) algorithm for estimation of co(variance) components in mixed models (Madsen and Jensen, 2008).

\section{Estimation of Breeding Values}

Genetic parameters obtained from the linear model were used for the breeding value estimation procedure. Sire EBV obtained from the multiple-trait linear animal model were used for correlation analyses with sire genomic EBV for traits of economic importance obtained from the official genomic evaluation of Canada (performed by the Canadian Dairy Network). Immune response traits used for the correlation included CMIR, AMIR, and overall IR. The average EBV for d 14 and 21 IgG1 response was used for AMIR to reflect both a primary antibody response as well as an immunological memory response. To have an EBV for overall immune responsiveness, an index was created with equal emphasis on 2 immunological traits, CMIR and the average EBV, for d 14 and 21 IgG1 responses for AMIR. Only associations with a value greater than 0.15 and $P$ $\leq 0.01$ are reported.

\section{RESULTS}

Descriptive statistics of the IR traits CMIR and AMIR at d 14 and 21 for IgG1 and IgG2 are presented in Table 1. The mean AMIR response was higher at $d$ 21 than 14 for both IgG1 and IgG2. This indicates the immunization regimen was efficacious, and the immunizations induced measurable primary and secondary antibody responses. 
Table 1. Descriptive statistics of immune response traits

\begin{tabular}{lllcccc}
\hline Trait $^{1}$ & Unit & No. & Mean & SD & Minimum & Maximum \\
\hline CMIR & mm & 445 & 1.550 & 0.317 & 1.051 & 3.537 \\
AMIR 14 IgG1 & OD $^{2}$ & 446 & 0.639 & 0.168 & 0.139 & 1.061 \\
AMIR 21 IgG1 & OD & 446 & 1.478 & 0.149 & 1.020 & 1.813 \\
AMIR 14 IgG2 & OD & 446 & 0.430 & 0.136 & 0.169 & 1.747 \\
AMIR 21 IgG2 & OD & 446 & 0.882 & 0.157 & 0.504 & 1.601 \\
\hline
\end{tabular}

${ }^{1} \mathrm{CMIR}=$ cell-mediated immune response, measured as increase in skin-fold thickness to a type-1 antigen; AMIR = antibody-mediated immune response at d 14 and 21 of the immunization protocol to a type- 2 antigen for serum IgG1 and IgG2, as measured by ELISA.

${ }^{2}$ Optical density units at $405 \mathrm{~nm}$.

The adaptive IR traits CMIR and AMIR were found to be moderately heritable. Table 2 shows the estimates of genetic, herd-technician, residual, and total variances, as well as heritability estimates from the single-trait analysis. In this study, the additive genetic variance was a larger component of the total variance for all AMIR traits compared with the herd-technician variance. However, for CMIR, herd-technician variance $\left(\sigma_{h t}^{2}=0.59\right)$ was a slightly larger component of total variance than genetic variance $\left(\sigma_{a}^{2}=0.53\right)$. The heritability of CMIR from the single-trait analysis was 0.16 $(\mathrm{SE}=0.14)$ and heritability of AMIR ranged from 0.14 to 0.38 ( $\mathrm{SE}=0.09-0.11$ ), depending on time in the immunization protocol and antibody isotype. Heritability of the secondary antibody response (d 21) was higher than primary (d 14) for both IgG1 and IgG2.

Estimates of heritability, genetic correlations, and residual correlations of the CMIR and AMIR are shown in Table 3. These heritability estimates have been averaged from a series of bivariate analyses and are in agreement with estimates from the single-trait analysis shown in Table 2. The same trend was found for AMIR traits: d 21 had higher heritability than d 14 for both antibody isotypes. The genetic correlations between CMIR and AMIR were negative at all time points $(-0.13$ to $-0.45, \mathrm{SE}=0.32-0.46)$ and the correlations between d 14 and 21 for IgG1 $(0.84, \mathrm{SE}=$ $0.17)$ and $\operatorname{IgG} 2(0.91, \mathrm{SE}=0.21)$ were positive and strong. Genetic correlations between IgG1 and IgG2 at d $14(0.99, \mathrm{SE}=0.65)$ and d $21(0.96, \mathrm{SE}=0.14)$ were positive and high.

The estimated phenotypic correlations between the IR traits are presented in Table 4. Similar trends were found as per the genetic correlations. Phenotypically, CMIR and AMIR tend to have no correlation at all time points and for each antibody $(-0.06-0.08)$. Estimated phenotypic correlations between d 14 and 21 for IgG1 (0.51) and IgG2 (0.73) were high. The estimated phenotypic correlations between IgG1 and IgG2 were 0.66 on $\mathrm{d} 14$ and 0.50 on $\mathrm{d} 21$.

Table 5 shows the correlations between overall IR, AMIR, and CMIR and routinely evaluated traits in Canada. In Canada, a higher EBV for a routinely evaluated trait is favorable. Therefore, all positive associations with IR are considered beneficial. Overall IR had positive correlations with number of services $(0.18)$ and first service to conception (0.17) but a negative correlation with calving ability (-0.19). The AMIR had beneficial associations with 56-d non-return rate (0.16), number of services (0.20), and first service to conception (0.18), but had negative associations with daughter calving ease $(-0.19)$ and gestation length $(-0.17)$. Daughter calving ease was beneficially associated with CMIR (0.17). For production traits, positive associations were found for CMIR with milk yield (0.16) and milk yield in first parity (0.15), but no significant associations were found with overall IR. Overall IR had negative correlations with the conformation trait teat length $(-0.20)$, as did CMIR $(-0.17)$. Fore teat place-

Table 2. Additive genetic variance $\left(\sigma_{a}^{2}\right)$, herd-technician variance $\left(\sigma_{h t}^{2}\right)$, residual variance $\left(\sigma_{e}^{2}\right)$, total variance, and heritability $\left(h^{2}\right)$ from a single-trait analysis (SE in parentheses)

\begin{tabular}{lccccc}
\hline Trait $^{1}$ & $\sigma_{a}^{2}$ & $\sigma_{h t}^{2}$ & $\sigma_{e}^{2}$ & Total & $h^{2}$ \\
\hline CMIR & 0.531 & 0.590 & 2.21 & 3.33 & $0.16(0.14)$ \\
AMIR 14 IgG1 & 676 & 250 & 1,550 & 2,470 & $0.27(0.10)$ \\
AMIR 21 IgG1 & 758 & 158 & 1,100 & 2,020 & $0.38(0.11)$ \\
AMIR 14 IgG2 & 438 & 34.4 & 2,650 & 3,130 & $0.14(0.09)$ \\
AMIR 21 IgG2 & 1,560 & 47.1 & 2,440 & 4,050 & $0.38(0.10)$ \\
\hline
\end{tabular}

${ }^{1} \mathrm{CMIR}=$ cell-mediated immune response, measured as increase in skin-fold thickness to a type-1 antigen; $\mathrm{AMIR}=$ antibody-mediated immune response at d 14 and 21 of the immunization protocol to a type- 2 antigen for serum IgG1 and IgG2, as measured by ELISA. 
Table 3. Average of heritability (diagonal), genetic (above diagonal), and residual (below diagonal) correlations of immune response traits (SE in parentheses)

\begin{tabular}{|c|c|c|c|c|c|}
\hline Trait $^{1}$ & CMIR & $\begin{array}{l}\text { AMIR } 14 \\
\text { IgG1 }\end{array}$ & $\begin{array}{l}\text { AMIR } 21 \\
\text { IgG1 }\end{array}$ & $\begin{array}{l}\text { AMIR } 14 \\
\text { IgG2 }\end{array}$ & $\begin{array}{l}\text { AMIR } 21 \\
\text { IgG2 }\end{array}$ \\
\hline CMIR & $0.19(0.10)$ & $-0.45(0.32)$ & $-0.13(0.37)$ & $-0.37(0.46)$ & $-0.26(0.33)$ \\
\hline AMIR 14 IgG1 & $0.27(0.16)$ & $0.29(0.10)$ & $0.84(0.17)$ & $0.99(0.65)$ & $0.67(0.20)$ \\
\hline AMIR 21 IgG1 & $-0.05(0.16)$ & $0.42(0.11)$ & $0.34(0.11)$ & $0.57(0.35)$ & $0.96(0.14)$ \\
\hline AMIR 14 IgG2 & $0.10(0.11)$ & $0.64(0.08)$ & $0.18(0.14)^{\prime}$ & $0.16(0.09)$ & $0.91(0.21)$ \\
\hline AMIR 21 IgG2 & $0.13(0.14)$ & $0.34(0.12)$ & $0.23(0.13)$ & $0.73(0.06)$ & $0.41(0.10)$ \\
\hline
\end{tabular}

${ }^{1} \mathrm{CMIR}=$ cell-mediated immune response, measured as increase in skin-fold thickness to a type-1 antigen; $\mathrm{AMIR}=$ antibody-mediated immune response at $\mathrm{d} 14$ and 21 of the immunization protocol to a type- 2 antigen for serum IgG1 and IgG2, as measured by ELISA.

ment was beneficially associated with CMIR (0.16) and height at front end was beneficially associated with AMIR (0.16).

Longevity traits were found to be beneficially associated with AMIR $(P \leq 0.05)$. Multiple measures of direct herd life were positively correlated with the AMIR trait (0.13-0.14); however, no significant correlations were found with overall immune responsiveness. No association of IR with SCS was noted.

\section{DISCUSSION}

Immune response traits were found to be moderately heritable in commercial Holsteins from across Canada. Previous heritability estimates of serum antibody in Holstein cows were found to range from 0.32 to 0.64 , depending on time relative to calving (Wagter et al., 2000) and from 0.25 to 0.42 , depending on time in the immunization protocol and the test antigen (Hernández et al., 2006). Heritability of CMIR was found to range between 0.19 and 0.49 , again depending on time and test antigen (Hernández et al., 2006). Further, the heritability of general immunity in dairy cattle has been estimated at 0.20 (Abdel-Azim et al., 2005). The heritability of CMIR and AMIR from numerous herds on a national scale found in this study confirms results of similar studies on 1 or a few herds within 1 region.

The heritability of the adaptive IR traits CMIR and AMIR in dairy cattle are consistent with estimates in other species. Heritability of AMIR in mice selectively bred for high and low AMIR to sheep erythrocytes ranged from 0.18 to 0.36 (Feingold et al., 1976) and in guinea pigs was estimated to be 0.18 (Ibañez et al., 1980). Estimates in chickens were slightly higher than in the other species and ranged from 0.40 to 0.66 , depending on the antibody (Sarker et al., 1999). More recently, Yorkshire pigs were bred simultaneously for high AMIR and high CMIR, and heritability estimates were 0.16 and 0.27 , respectively (Wilkie and Mallard, 1999). Taken together, the heritability of these traits across species indicates the possibility of genetic selection for enhanced IR in dairy cattle as has been found in mice, guinea pigs, chickens, and pigs.

The genetic correlations between CMIR and AMIR were negative at all time points, and phenotypic correlations were approximately 0 . The cytokines that promote CMIR tend to dampen AMIR, and vice versa. Therefore, a negative genetic correlation between the traits is expected. Negative correlations between CMIR and AMIR have been established in other species. In the 1970s, Biozzi et al. (1979) selectively bred mice for high or low antibody responses and found that highAMIR mice had diminished CMIR, as measured by macrophage activity, and vice versa; low-AMIR mice had enhanced CMIR (Mouton et al., 1984). A similar trend was found in chickens also selectively bred for high and low antibody response. Chickens with high AMIR had lower CMIR, and low-AMIR chickens had higher CMIR assessed by degree of splenomegaly (Sarker et al., 2000). These divergent selection experiments in mice and chickens demonstrate the antagonistic genetic control of CMIR and AMIR, as further evidenced by the negative genetic correlation found in this study in dairy cattle. Because CMIR and AMIR provide protec-

Table 4. Estimated phenotypic correlations of immune response traits

\begin{tabular}{lcccc}
\hline & AMIR 14 & AMIR 21 & AMIR 14 & AMIR 21 \\
Trait $^{1}$ & IgG1 & IgG1 & IgG2 & IgG2 \\
\hline CMIR & 0.08 & -0.06 & 0.02 & 0.02 \\
AMIR 14 IgG1 & & 0.51 & 0.66 & 0.53 \\
AMIR 21 IgG1 & & & 0.25 & 0.50 \\
AMIR 14 IgG2 & & & 0.73 \\
\hline
\end{tabular}

${ }^{1} \mathrm{CMIR}=$ cell-mediated immune response, measured as increase in skin-fold thickness to a type-1 antigen; $\mathrm{AMIR}=$ antibody-mediated immune response at $\mathrm{d} 14$ and 21 of the immunization protocol to a type- 2 antigen for serum IgG1 and IgG2, as measured by ELISA. 
Table 5. Correlations between genetic evaluations for immune response (IR) traits and routinely evaluated traits by the Canadian Dairy Network (Guelph, ON, Canada)

\begin{tabular}{|c|c|c|c|c|}
\hline $\begin{array}{l}\text { Routinely } \\
\text { evaluated trait }{ }^{1}\end{array}$ & $\begin{array}{c}\text { Number } \\
\text { of sires }\end{array}$ & $\begin{array}{c}\text { Overall } \\
\mathrm{IR}^{2}\end{array}$ & $\mathrm{AMIR}^{3}$ & $\mathrm{CMIR}^{4}$ \\
\hline \multicolumn{5}{|l|}{ Reproduction heifer } \\
\hline Calving ability & 260 & -0.19 & - & - \\
\hline 56-d non-return rate & 260 & - & 0.16 & - \\
\hline Number of services & 260 & 0.18 & 0.20 & - \\
\hline First service to conception & 260 & 0.17 & 0.18 & - \\
\hline Gestation length & 260 & - & - & 0.17 \\
\hline Daughter calving ease & 260 & - & -0.19 & - \\
\hline \multicolumn{5}{|l|}{ Reproduction cow } \\
\hline Gestation length & 282 & - & -0.17 & - \\
\hline \multicolumn{5}{|l|}{ Production } \\
\hline Milk yield & 286 & - & - & 0.16 \\
\hline Milk yield (first parity) & 286 & - & - & 0.15 \\
\hline \multicolumn{5}{|l|}{ Conformation } \\
\hline Fore teat placement & 271 & - & - & 0.16 \\
\hline Teat length & 271 & -0.20 & - & -0.17 \\
\hline Height at front end & 269 & - & 0.16 & - \\
\hline
\end{tabular}

${ }^{1}$ All positive correlations are considered beneficial for routinely evaluated traits in Canada.

${ }^{2}$ Overall immune response EBV.

${ }^{3} \mathrm{AMIR}=$ antibody-mediated immune response average of d 14 and $21 \mathrm{EBV}$ for serum IgG1 response to the type-2 test antigen.

${ }^{4} \mathrm{CMIR}=$ cell-mediated immune response EBV.

tion to different pathogens, the results emphasize the importance of considering both CMIR and AMIR to genetically improve IR in dairy cattle to provide protection to a multitude of immunological challenges, as suggested previously (Wilkie and Mallard, 1999).

The d 14 and 21 antibody data were found to be highly genetically correlated for both IgG1 and IgG2. Heritability at d 21 for both IgG1 and IgG2 was higher than at $\mathrm{d} 14$, indicating a more reliable breeding value would be estimated from the IR phenotype at d 21 . However, to obtain an antibody phenotype at d 21, cows were re-immunized at $\mathrm{d} 14$, requiring a visit to the farm. For ease of implementation of IR testing, the high genetic correlation indicates that it may be feasible to decrease the sampling period for AMIR to $14 \mathrm{~d}$.

The immunoglobulin isotypes IgG1 and $\operatorname{IgG} 2$ were positively genetically and phenotypically correlated at d 14 and 21. This is likely due to the fact that this response was measured to a single test antigen. This may not be the case when response to diverse type1 and type-2 antigens are measured (Corbeil, 2002). Phenotypic correlations between IgG1 and IgG2 to the type-2 test antigen HEWL used in the current study have previously been estimated to be 0.88 on d 14 and 0.59 on d 21 (Heriazon et al., 2011). It is also noteworthy that total serum IgG1 and IgG2 immunoglobulin isotypes were found to have a genetic correlation of 0.86 in Canadian Holsteins (Mazengera et al., 1985).

This IR study was part of a larger study through the CBMRN. The overall goal of the CBMRN was to decrease the incidence of mastitis, decrease financial losses, and maintain quality milk on Canadian dairy farms. Pedigree structure was not prioritized for IR sampling, and it should, therefore, be noted the majority of sires used in the correlation analysis had only 2 daughters with IR data. Also, the relatively small number of animals in this study contributed to the large standard errors of the genetic parameter estimates. Although the data size and structure is limited, the results provide novel insight to the correlation of IR with other traits routinely evaluated in Canada.

Routinely evaluated traits in Canada, with the exception of SCS, are scored to have a higher EBV being favorable. Therefore, all positive associations between economically important traits and IR indicate breeding for enhanced IR would have a beneficial effect on the trait. Results of this study suggest that selecting for general overall immune responsiveness may have a positive association with reproductive traits such as number of services and first service to conception. Breeding for IR may decrease the number of services and first service to conception. Diseases such as mastitis have also been shown to have a negative effect on reproductive performance (Ahmadzadeh et al., 2009). It, therefore, might be expected that improvement in IR that decreases diseases like mastitis would have beneficial effects on reproductive traits.

The CMIR had significant correlations with the production traits milk yield and milk yield in first parity. No significant associations with overall IR or AMIR were found. Previously, a study evaluating genetic correlations between production traits and IR found significant associations between AMIR and fat percentage (0.18) and CMIR and protein percentage $(-0.15)$ 
(Heriazon, 2007). Another study that phenotypically classified Canadian Holsteins based on AMIR found that high-AMIR cows in first parity had lower fat and protein yields than low-immune responders and highAMIR cows in parity 3 or greater had higher milk yield (Wagter et al., 2003). To achieve broad-based disease resistance or protection to type- 1 and type- 2 pathogens, it is important to enhance both branches of the adaptive immune system (AMIR and CMIR). The mixed results of associations of AMIR and CMIR with production traits, together with the lack of association found with production and overall IR found in this study, indicate that breeding for overall IR may not affect production.

Udder conformation traits have been associated with mastitis incidence. Shallow udders and strongly attached fore udders have been associated with lower mastitis occurrence (Nash et al., 2000). In the current study, overall IR was associated with 1 trait, teat length, and the reason for this association is unclear.

It is worth noting that longevity was found to be beneficially associated with AMIR, measured as multiple measures of direct herd life. This has not been previously reported and may be worth further investigation.

The adaptive IR traits measured in this study did not have significant associations with SCS. Somatic cell score is a measure of the number of cells present in milk and can be used as an indicator of infection causing mastitis. It is generally composed of neutrophils and macrophages that migrate to the udder to act as a first line of defense against pathogenic microorganisms (Oviedo-Boyso et al., 2007). During a microbial infection, neutrophils are recruited to the mammary gland and form the vast majority of the somatic cells (Kehrli and Shuster, 1994). Neutrophils are considered part of the innate immune system, whereas the IR traits CMIR and AMIR measured in this study are part of the adaptive immune system, mediated by $\mathrm{T}$ cells and $\mathrm{B}$ cells. Therefore, it is predictable that no association would exist between the adaptive IR traits CMIR and AMIR measured in this study and SCS.

Current breeding strategies to decrease disease in dairy cattle include direct and indirect selection methods. Mastitis is one of the most costly and complex diseases affecting dairy cattle. Its complexity lies in the multitude of mastitis-causing pathogens which use diverse mechanisms to infect the host and can cause clinical or subclinical mastitis, which is associated with a range of physiological symptoms that affect milk yield and quality. Scandinavian countries have led the way in direct selection for mastitis resistance with well-established health-recording systems (Heringstad et al., 2000). Somatic cell score is positively correlated with mastitis (Bloemhof et al., 2009) and has a higher heritability than mastitis resistance. Somatic cell score is, therefore, used in most countries as an indirect selection method for mastitis resistance. Breeding for mastitis resistance or SCS, in coordination with good management practices, have been effective at impeding increases in the incidence of clinical mastitis. However, a shift in relative importance of various mastitis-causing pathogens has also been noted (Bradley, 2002). Because cattle respond to challenge with different immunological mechanisms, resistance against one mastitis-causing pathogen may increase the risk of infection with others. Breeding for enhanced overall IR may allow dairy cattle to have dynamic protection to continually changing pathogenic challenges in the environment.

Direct selection against a combination of diseases has been suggested (Zwald et al., 2004). Problems associated with this approach include the high genetic variability of disease resistance and low heritability. Heritability of mastitis resistance was estimated between 0.02 to 0.06 , depending on the time relative to calving (Koeck et al., 2010). Heritability of other diseases such as retained placenta, reproductive diseases, and calving fever are slightly higher and have been averaged to be about 0.11 (Lund et al., 1994). A recent study estimated the heritability of milk antibody to Mycobacterium avium subspecies paratuberculosis as a method to use genetic selection for disease control. The heritability estimates ranged from 0.031 to 0.097 , depending on herd prevalence (van Hulzen et al., 2011). The low heritability of resistance traits indicates that genetic progress for resistance would be slow. Also, selection for specific disease resistance will likely leave individuals susceptible to other diseases, because antagonistic genetic correlations exist between IR traits required to control diverse pathogens. Another consideration is the potential for emerging pathogenic challenge, which could be associated with antimicrobial resistance. Selection for enhanced overall immune responsiveness possibly overcomes these problems associated with breeding for specific disease resistance in dairy cattle. Results of this study confirm the moderate heritability of IR in cattle, indicating genetic progress would be made relatively faster than selection for specific disease resistance. More importantly, breeding for balanced IR would likely enhance broad-based disease resistance to a variety of important and potential disease-causing organisms in dairy cattle.

\section{CONCLUSIONS}

The results of this study show that the adaptive IR traits CMIR and AMIR are heritable in commercial Canadian Holsteins. Estimates from this study are consistent with previous heritability estimates of IR in dairy cattle. However, the completeness of pedigree, 
larger volume of data than previous studies and the methodology used in the present study reflects the genetic parameters of IR of Canadian Holsteins more accurately than previous studies. As high immuneresponding dairy cattle have previously been associated with decreased occurrence of disease and improved response to vaccination, the moderate heritability of these traits suggests that it would be possible to breed cattle for improved immunity to minimize the impact of disease and improve overall health. The traits CMIR and AMIR were found to be negatively genetically correlated, emphasizing the importance of selecting cows on both IR traits to provide broad-based disease resistance to a multitude of organisms. The high genetic correlation between serum antibodies at the 2 time points tested indicates it may be possible to minimize the IR sampling protocol to $14 \mathrm{~d}$ instead of 21 d. Finally, overall IR was found to have positive correlations with the number of services and first service to conception, which may indicate a desirable genetic relationship exists between reproduction and IR that needs to be confirmed with further studies.

\section{ACKNOWLEDGMENTS}

This research is financed by grants to B. A. Mallard from the National Sciences and Engineering Research Council of Canada (Ottawa, ON, Canada); Alberta Milk (Edmonton, AB, Canada); Dairy Farmers of New Brunswick, Nova Scotia, Ontario, and Prince Edward Island; Novalait Inc. (Quebec, QC, Canada); Dairy Farmers of Canada (Ottawa, ON, Canada); DairyGen Council of Canadian Dairy Network (Guelph, ON, Canada); Agriculture and Agri-Food Canada (Ottawa, ON, Canada); Public Health Agency of Canada (Ottawa, ON, Canada); Technology PEI Inc. (Charlottetown, PEI, Canada); Université de Montréal (Montréal, QC, Canada); and University of Prince Edward Island (Charlottetown, PEI, Canada) through the Canadian Bovine Mastitis Research Network. K. A. ThompsonCrispi is funded by the Dairy Farmers of Ontario Doctoral Research Assistantship. Finally, we thank 2 anonymous reviewers for their helpful suggestions and comments.

\section{REFERENCES}

Abdel-Azim, G. A., A. E. Freeman, M. E. Kehrli Jr., S. C. Kelm, J. L. Burton, A. L. Kuck, and S. Schnell. 2005. Genetic basis and risk factors for infectious and noninfectious diseases in US Holsteins. I. Estimation of genetic parameters for single diseases and general health. J. Dairy Sci. 88:1199-1207.

Ahmadzadeh, A., F. Frago, B. Shafii, J. C. Dalton, W. J. Price, and M. A. McGuire. 2009. Effect of clinical mastitis and other diseases on reproductive performance of Holstein cows. Anim. Reprod. Sci. 112:273-282.
Biozzi, G., D. Mouton, A. M. Heumann, Y. Bouthillier, C. Stiffel, and J. C. Mevel. 1979. Genetic analysis of antibody responsiveness to sheep erythrocytes in crosses between lines of mice selected for high or low antibody synthesis. Immunology 36:427-438.

Bloemhof, S., G. de Jong, and Y. de Haas. 2009. Genetic parameters for clinical mastitis in the first three lactations of Dutch Holstein cattle. Vet. Microbiol. 134:165-171.

Bradley, A. 2002. Bovine mastitis: An evolving disease. Vet. J. 164:116-128.

Brown, W. C., A. C. Rice-Ficht, and D. M. Estes. 1998. Bovine type 1 and type 2 responses. Vet. Immunol. Immunopathol. 63:45-55.

Corbeil, L. B. 2002. Antibodies as effectors. Vet. Immunol. Immunopathol. 87:169-175.

Crawley, A. M., B. Mallard, and B. N. Wilkie. 2005. Genetic selection for high and low immune response in pigs: Effects on immunoglobulin isotype expression. Vet. Immunol. Immunopathol. 108:71-76.

De La Paz, J. 2008. Using humoral and cellular response to novel antigens in periparturient dairy cows as a measure of genetic disease resistance in dairy cows. MSc Thesis. University of Florida, Gainesville.

Estes, D. M., and W. C. Brown. 2002. Type 1 and type 2 responses in regulation of Ig isotype expression in cattle. Vet. Immunol. Immunopathol. 90:1-10.

Feingold, N., J. Feingold, D. Mouton, Y. Bouthillier, C. Stiffel, and G. Biozzi. 1976. Polygenic regulation of antibody synthesis to sheep erythrocytes in the mouse: A genetic analysis. Eur. J. Immunol. $6: 43-51$.

Heriazon, A. 2007. Phenotypic and genetic parameters of acquired immune responses to improve dairy cattle health. $\mathrm{PhD}$ Thesis. University of Guelph, Guelph, ON, Canada.

Heriazon, A., K. Hamilton, J. Huffman, B. N. Wilkie, W. Sears, M. Quinton, and B. A. Mallard. 2011. Immunoglobulin isotypes of lactating Holstein cows classified as high, average, and low type-1 or -2 immune responders. Vet. Immunol. Immunopathol. 144:259 269.

Heriazon, A., K. A. Thompson, B. N. Wilkie, W. Mathes-Sears, M. Quinton, and B. A. Mallard. 2009a. Antibody to ovalbumin and delayed-type hypersensitivity to Candida albicans and mycobacteria in lactating Holstein cows using Quil A or Freund's complete adjuvant. Vet. Immunol. Immunopathol. 127:220-227.

Heriazon, A., J. A. Yager, W. Sears, and B. A. Mallard. 2009b. Induction of delayed-type hypersensitivity and interferon-gamma to Candida albicans and anti-hen-egg white lysozyme antibody as phenotypic markers of enhanced bovine immune response. Vet. Immunol. Immunopathol. 129:93-100.

Heringstad, B., Y. M. Chang, D. Gianola, and G. Klemetsdal. 2005 Genetic association between susceptibility to clinical mastitis and protein yield in Norwegian dairy cattle. J. Dairy Sci. 88:15091514.

Heringstad, B., G. Klemetsdal, and J. Ruane. 2000. Selection for mastitis resistance in dairy cattle: A review with focus on the situation in the Nordic countries. Livest. Prod. Sci. 64:95-106.

Hernández, A., M. Quinton, F. Miglior, and B. A. Mallard. 2006. Genetic parameters of dairy cattle immune response traits. Pages 15 18 in Proc. 8th World Congress on Genetics Applied to Livestock Production, Belo Horizonte, Minas Gerais, Brazil. WCGALP, Belo Horizonte, Brazil.

Hernández, A., J. A. Yager, B. N. Wilkie, K. E. Leslie, and B. A. Mallard. 2005. Evaluation of bovine cutaneous delayed-type hypersensitivity (DTH) to various test antigens and a mitogen using several adjuvants. Vet. Immunol. Immunopathol. 104:45-58.

Hine, B. C., S. L. Cartwright, and B. A. Mallard. 2011. Effect of age and pregnancy status on adaptive immune responses of Canadian Holstein replacement heifers. J. Dairy Sci. 94:981-991.

Ibañez, O. M., M. S. Reis, M. Gennari, V. C. A. Ferreira, O. A. Sant'Anna, M. Siqueira, and G. Biozzi. 1980. Selective breeding of high and low antibody-responder lines of guinea pigs. Immunogenetics 10:283-293.

Kehrli, M. E., Jr., and D. E. Shuster. 1994. Factors affecting milk somatic cells and their role in health of the bovine mammary gland J. Dairy Sci. 77:619-627. 
Koeck, A., B. Heringstad, C. Egger-Danner, C. Fuerst, P. Winter, and B. Fuerst-Waltl. 2010. Genetic analysis of clinical mastitis and somatic cell count traits in Austrian Fleckvieh cows. J. Dairy Sci. 93:5987-5995.

Lund, T., F. Miglior, J. C. Dekkers, and E. B. Burnside. 1994. Genetic relationships between clinical mastitis, somatic cell count, and udder conformation in Danish Holsteins. Livest. Prod. Sci. $39: 243-251$

Madsen, P., and J. Jensen. 2008. DMU: An user's guide. A package for analysing multivariate mixed models. Version 6, release 4.7. Faculty Agricultural Sciences (DJF), Foulum, Denmark. Accessed January 2010. http://www.dmu.agrsci.dk/dmuv6_guide-R4-6-7. pdf.

Mallard, B. A., H. Atalla, S. Cartwright, B. C. Hine, B. Hussey, M. Paibomesai, K. A. Thompson-Crispi, and L. Wagter-Lesperance. 2011. Genetic and epigenetic regulation of the bovine immune system: Practical implications of the high immune response technology. Pages 53-63 in Proc. National Mastitis Council 50th Annual Meeting. National Mastitis Council, Verona, WI.

Mallard, B. A., E. B. Burnside, J. H. Burton, and B. N. Wilkie. 1983. Variation in serum immunoglobulins in Canadian Holstein-Friesians. J. Dairy Sci. 66:862-866.

Mazengera, K. E., B. W. Kennedy, E. B. Burnside, B. N. Wilkie, and J. H. Burton. 1985. Genetic parameters of bovine serum immunoglobulins. J. Dairy Sci. 68:2309-2314.

Mouton, D., Y. Bouthillier, J. C. Mevel, and G. Biozzi. 1984. Genetic selection for antibody responsiveness in mice: Further evidence for inverse modification of macrophage catabolic activity without alteration of the expression of T-cell-mediated immunity. Ann. Immunol. (Paris) 135D:173-186.

Nash, D. L., G. W. Rogers, J. B. Cooper, G. L. Hargrove, J. F. Keown, and L. B. Hansen. 2000. Heritability of clinical mastitis incidence and relationships with sire transmitting abilities for somatic cell score, udder type traits, productive life, and protein yield. J. Dairy Sci. 83:2350-2360.

Oviedo-Boyso, J., J. J. Valdez-Alarcón, M. Cajero-Juárez, A. OchoaZarzosa, J. E. López-Meza, A. Bravo-Patiño, and V. M. Baizabal-Aguirre. 2007. Innate immune response of bovine mammary gland to pathogenic bacteria responsible for mastitis. J. Infect. 54:399-409.
Reyher, K. K., S. Dufour, H. W. Barkema, C. L. Des, T. J. Devries, I. R. Dohoo, G. P. Keefe, J. P. Roy, and D. T. Scholl. 2011. The National Cohort of Dairy Farms - A data collection platform for mastitis research in Canada. J. Dairy Sci. 94:1616-1626.

Sarker, N., M. Tsudzuki, M. Nishibori, and Y. Yamamoto. 1999. Direct and correlated response to divergent selection for serum immunoglobulin $\mathrm{M}$ and $\mathrm{G}$ levels in chickens. Poult. Sci. 78:1-7.

Sarker, N., M. Tsudzuki, M. Nishibori, H. Yasue, and Y. Yamamoto. 2000. Cell-mediated and humoral immunity and phagocytic ability in chicken lines divergently selected for serum immunoglobulin $\mathrm{M}$ and G levels. Poult. Sci. 79:1705-1709.

Shook, G. E. 1989. Selection for disease resistance. J. Dairy Sci. $72: 1349-1362$

Thompson-Crispi, K. A., and B. A. Mallard. 2011. Type 1 and type 2 immune response profiles of commercial dairy cows in four regions of Canada. Can. J. Vet. Res. In press.

van Hulzen, K. J. E., M. Nielen, A. P. Koets, G. de Jong, J. A. M. van Arendonk, and H. C. M. Heuven. 2011. Effect of herd prevalence on heritability estimates of antibody response to Mycobacterium avium subspecies paratuberculosis. J. Dairy Sci. 94:992-997.

Wagter, L. C., B. A. Mallard, B. N. Wilkie, K. E. Leslie, P. J. Boettcher, and J. C. M. Dekkers. 2000. A quantitative approach to classifying Holstein cows based on antibody responsiveness and its relationship to peripartum mastitis occurrence. J. Dairy Sci. $83: 488-498$

Wagter, L. C., B. A. Mallard, B. N. Wilkie, K. E. Leslie, P. J. Boettcher, and J. C. M. Dekkers. 2003. The relationship between milk production and antibody response to ovalbumin during the peripartum period. J. Dairy Sci. 86:169-173.

Wagter-Lesperance, L., and B. Mallard, inventors. 2007. Method of identifying high immune response animals. University of Guelph, assignee. US Pat. No. 7,258,858.

Wilkie, B., and B. Mallard. 1999. Selection for high immune response: An alternative approach to animal health maintenance? Vet. Immunol. Immunopathol. 72:231-235.

Zwald, N. R., K. A. Weigel, Y. M. Chang, R. D. Welper, and J. S. Clay. 2004. Genetic selection for health traits using producerrecorded data. I. Incidence rates, heritability estimates, and sire breeding values. J. Dairy Sci. 87:4287-4294. 